\title{
Fabrication of Heat Storage Pellets Consisting of a Metallic Latent Heat Storage Microcapsule and an $\mathrm{Al}_{2} \mathrm{O}_{3}$ Matrix
}

\author{
Hiroki SAKAI, ${ }^{1)}$ Ade KURNIAWAN ${ }^{2)}$ Tomohiro AKIYAMA ${ }^{2)}$ and Takahiro NOMURA ${ }^{2) *}$ \\ 1) Graduate School of Engineering, Hokkaido University, Kita 13 Nishi 8, Kita-ku, Sapporo, Hokkaido, 060-8628 Japan. \\ 2) Faculty of Engineering, Hokkaido University, Kita 13 Nishi 8, Kita-ku, Sapporo, Hokkaido, 060-8628 Japan.
}

(Received on January 7, 2020; accepted on March 4, 2020)

\begin{abstract}
Energy efficiency is fundamental in the steel industry. Latent heat storage (LHS) systems with phase change materials (PCM) are attractive technologies for the recovery and utilization of heat, especially for the development of high-temperature thermal energy storage system. This paper describes fabrication of LHS pellets for high-temperature applications using metallic microencapsulated PCM (MEPCM). The LHS pellets consist of Al-Si PCM parts and an $\mathrm{Al}_{2} \mathrm{O}_{3}$ matrix. The pellets were fabricated by mixing MEPCM with sinterable alumina. The powder mixture was then pelletized and sintered at different pressures and atmospheric conditions, respectively. Some MEPCM in the pellets remained spherical after being sintered at $1000^{\circ} \mathrm{C}$, a high-temperature condition above the PCM melting temperature. All fabricated pellets exhibited latent heat of $\mathrm{PCM}$ at the melting point of the $\mathrm{PCM}$, about $577^{\circ} \mathrm{C}$. The maximum value of latent heat was $73.5 \mathrm{~J} \mathrm{~g}^{-1}$. This was observed for the LHS pellet pelletized at $20 \mathrm{MPa}$ and sintered under $\mathrm{O}_{2}$ atmosphere. Therefore, this study presents a great material for high-temperature thermal energy storage systems in the steel industry.
\end{abstract}

KEY WORDS: steelmaking; high temperature waste heat recovery; phase change material.

\section{Introduction}

The ironmaking industry plays a large role in global $\mathrm{CO}_{2}$ emission trends. This is because carbon is used to reduce iron ores, forming $\mathrm{CO}_{2}$ during steel production. For this reason, many efforts have been made to make the process energy efficient. ${ }^{1,2)}$ For example, exhaust heat recovery by chemical reaction such as methanol synthesis ${ }^{3,4)}$ or stream reforming of methane ${ }^{5-7)}$ were studied. Moreover, using slag as heat source ${ }^{8-10)}$ were attempted. Large amounts of energy are used in ironmaking factories. Some of this energy is transferred to the products and some is lost as thermal energy. In ironmaking process, there are many exothermic and endothermic reactions. Effective utilization of thermal energy is necessary to develop iron with great efficiency.

To utilize the lost thermal energy efficiently, unutilized exhaust heat needs to be delivered and used in the heatconsuming processes. It is difficult to combine endothermic and exothermic processes directly because of spatial gaps and time gaps between the supply and demand of energy. Moreover, exhaust heat from batch process is unsuitable for a stable heat source because of the interval. Although large amounts of heat are emitted in the ironmaking plant,

* Corresponding author: E-mail: nms-tropy@eng.hokudai.ac.jp intermittency makes it difficult to channel it as a heat source. Thermal energy storage (TES) techniques have received great attention as solutions for challenges relating to the gaps and intermittency. TES works as a stable energy buffer and can be used for many processes. ${ }^{11-13)}$

There is a limitation of space in the ironmaking plant, thus high heat capacity TES techniques are desirable. Traditional sensible heat storage techniques do not have enough heat storage density. As a result of this, they are not suitable for ironmaking. Latent heat storage (LHS) systems are TES techniques which use the fusion heat of phase change material (PCM). LHS has a high storage density with only small temperature changes, making it favorable for ironmaking. This is because PCM can store more heat as latent heat than sensible heat by several ten times around phase change temperature. For instance, specific heat of $\mathrm{Al}_{2} \mathrm{O}_{3}$, a traditional high temperature heat storage material, is $1.17 \mathrm{~J} \mathrm{~g}^{-1} \mathrm{~K}^{-1}$. On the other hand, latent heat of $\mathrm{Al}-25$ mass $\% \mathrm{Si}^{14}{ }^{14} \mathrm{PCM}$ melting at $577^{\circ} \mathrm{C}$, is $432 \mathrm{~J} \mathrm{~g}^{-1}$. Moreover, LHS has two other advantages, as referred to in previous literature: ${ }^{15-17)}$ 1) When storing heat from the phase transition, the temperature remains constant; 2) The TES can be performed using only heat, without the need for additional reactions. This simplifies the system. These advantages have led to some studies on TES with LHS for applications in the ironmaking 
industry. The feasibility of heat transportation systems have been studied using erythritol, sodium acetate trihydrate, ${ }^{18)}$ or binary eutectic mixture $\mathrm{NaOH} / \mathrm{Na}_{2} \mathrm{CO}_{3}{ }^{11)}$ as PCMs.

Considering the second law of thermodynamics, the higher the temperature, the higher the energy. Heat sources at higher temperature are desired to promote higher efficiencies of energy recovery in the plant. LHS stores heat around the PCM melting temperature. Thus, PCMs with high melting temperatures are needed to develop high temperature LHS systems. Metals and metal alloys are candidates for high temperature PCMs. Studies to estimate the capability of $\mathrm{Mg}-\mathrm{Zn},{ }^{19)} \mathrm{Zn}-\mathrm{Mg}-\mathrm{Al},{ }^{20)} \mathrm{Al}-\mathrm{Si}^{21,22)}$ and $\mathrm{Cu}-\mathrm{Mg}-\mathrm{Si}^{23)}$ alloys were reported. Numerical simulation was used to mitigate exhaust heat flow from the electric arc furnace ${ }^{12,24)}$ and billet reheating furnace ${ }^{25)}$ using a metallic PCM. Previous research suggests the use of metal alloy PCMs as a thermal buffer for heat recovery in endothermic chemical reactions. $^{26-28)}$

We developed and focused on alloy microencapsulated PCM (MEPCM) in this study. The MEPCM is composed of an alloy PCM core, such as $\mathrm{Al}^{29)}$ and $\mathrm{Al}-\mathrm{Si}^{30-33)}$ and a ceramic $\mathrm{Al}_{2} \mathrm{O}_{3}$ shell with $30-40 \mu$ m diameter. This MEPCM has good stability, allowing for its use as a ceramic powder. Various methods can be used to fabricate the MEPCM heat storage structure.

In this study we used Al-Si alloy MEPCM to fabricate an LHS structure for use at high temperatures. The structure was expected to consist of an $\mathrm{Al}_{2} \mathrm{O}_{3}$ matrix and an $\mathrm{Al}-\mathrm{Si}$ PCM capsulated within an $\mathrm{Al}_{2} \mathrm{O}_{3}$ shell. An LHS pellet was fabricated by mixing MEPCM with $\mathrm{Al}_{2} \mathrm{O}_{3}$, and then applying compression and heat.

\section{Experimental Method}

\subsection{Materials}

Microparticles of Al-25 mass $\% \mathrm{Si}$ with a mean diameter of $36.3 \mu \mathrm{m}$ were prepared using the spinning disk atomization method (purity: $99.0 \%, \mathrm{~T}_{\mathrm{m}}: 577^{\circ} \mathrm{C}, \mathrm{L}: 432 \mathrm{~J} \mathrm{~g}^{-1}$, Hikari Material Industry Co. Ld.). They were used as raw materials.

$\mathrm{Al}(\mathrm{OH})_{3}$ powder (Kojundo Chemical Laboratory Co., Ltd, Purity: 99.99\%) was used as an additive to form the stable shell of MEPCM.

Sinterable alumina (SA) $(2.44 \mu \mathrm{m}$, purity $99.87 \%$, purchased from Nippon Light Metal Co. Ltd.) was used as a matrix material for the heat storage pellets.

\subsection{Preparation of MEPCM Precursor}

A MEPCM precursor was prepared following a previously-reported method. ${ }^{32)}$ Firstly, boehmite treatment of the Al-25 mass\% Si particles was conducted in boiling distilled water. $3.33 \mathrm{~g} \mathrm{~L}^{-1} \mathrm{Al}(\mathrm{OH})_{3}$ was added at a constant $\mathrm{pH}$ of 8 for $3 \mathrm{~h}$, to form a precursor shell on the surface. The $\mathrm{pH}$ value was adjusted by adding $\mathrm{NH}_{3} \cdot \mathrm{H}_{2} \mathrm{O}$ to the solution. The solution was then cooled to $75^{\circ} \mathrm{C}$ and this temperature was maintained for $16 \mathrm{~h}$. After filtration and drying, the MEPCM precursor was then obtained.

\subsection{Fabrication of Heat Storage Pellets}

The MEPCM precursor and SA were mixed, pressed, sintered, and finally heat storage pellets were prepared. Firstly,
Table 1. The name of the latent heat storage pellets with different fabrication situation. All heat storage pellets were made from the same mixed powder of MEPCM precursor and SA.

\begin{tabular}{ccc}
\hline Name of the products & Pelletized pressure & Sintering atmosphere \\
\hline $20 \mathrm{MPa}$-air & $20 \mathrm{MPa}$ & Air \\
$20 \mathrm{MPa}-\mathrm{O}_{2}$ & $20 \mathrm{MPa}$ & $\mathrm{O}_{2}$ \\
$50 \mathrm{MPa}$-air & $50 \mathrm{MPa}$ & Air \\
$50 \mathrm{MPa}-\mathrm{O}_{2}$ & $50 \mathrm{MPa}$ & $\mathrm{O}_{2}$ \\
\hline
\end{tabular}

MEPCM precursor and the SA were weighed at 1:1 and mixed with a planetary ball mill at a speed of $100 \mathrm{rpm}$ for $15 \mathrm{~min}$. Then the mixed powder was shaped into cylindrical pellets with diameter of $10 \mathrm{~mm}$ and height of 3.2-3.4 $\mathrm{mm}$ by pressing at room temperature at 20 or $50 \mathrm{MPa}$. Finally, the green pellets were heated to $1300^{\circ} \mathrm{C}$ and this temperature was maintained for $3 \mathrm{~h}$ under air or atmospheric $\mathrm{O}_{2}$. For simplicity, hereafter, the fabricated heat storage pellets are labeled as "x MPa-atmosphere" where $\mathrm{x}$ means the pelletized pressure and atmosphere is sintering atmosphere; air or $\mathrm{O}_{2}$. Table 1 shows the list of the products. For example, $20 \mathrm{MPa}$-air means heat storage pellets pelletized at $20 \mathrm{MPa}$ and sintered under air atmosphere.

\subsection{Characterization}

Scanning electron microscopy (SEM, JEOL, JSM7001FA) and energy dispersive spectroscopy (EDS) were used to characterize the surface structure of the synthesized composites. The phase composition was determined using powder X-ray diffraction (XRD) with a one-dimensional (1D) silicon-strip detector (Rigaku Miniflex600, D/teX Ultra2, $\mathrm{Cu} \mathrm{K} \alpha$ ). Their latent heat of fusion was measured using a differential scanning calorimeter (TG-DSC) (Mettler Toledo TGA-DSC-3); the samples were heated and cooled at rate of $5^{\circ} \mathrm{C} \mathrm{min}^{-1}$ in an $\mathrm{Ar}$ atmosphere during this process.

\section{Results \& Discussions}

\subsection{Structural Characterization of the Heat Storage Pellets}

Figure 1 shows images of the heat storage pellets (which consisted of MEPCM and SA) when pelletized and sintered under different pressures and atmospheres, respectively:

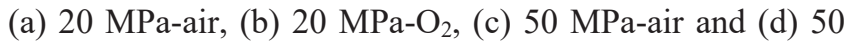
$\mathrm{MPa}-\mathrm{O}_{2}$. Despite having a higher sintering temperature than the melting temperature of the MEPCM, no agglomerations of metal were observed on the surface of the pellets. The sintering temperature was higher than $1000^{\circ} \mathrm{C}$. Leakage or combustion of liquid PCM was expected at this high sintering temperature. However, as shown in Fig. 1, agglomeration of metal was not observed and these pellets maintained their shape after sintering.

Figure 2 shows SEM images of the pellets fabricated under different conditions. Figure 2 shows that each pellet had a spherical structure with nearly the same diameter of raw PCM inside. This result indicates that some MEPCM kept their spherical shape in the heat storage pellets. Figure 3 shows SEM images and elemental mappings of the cross 

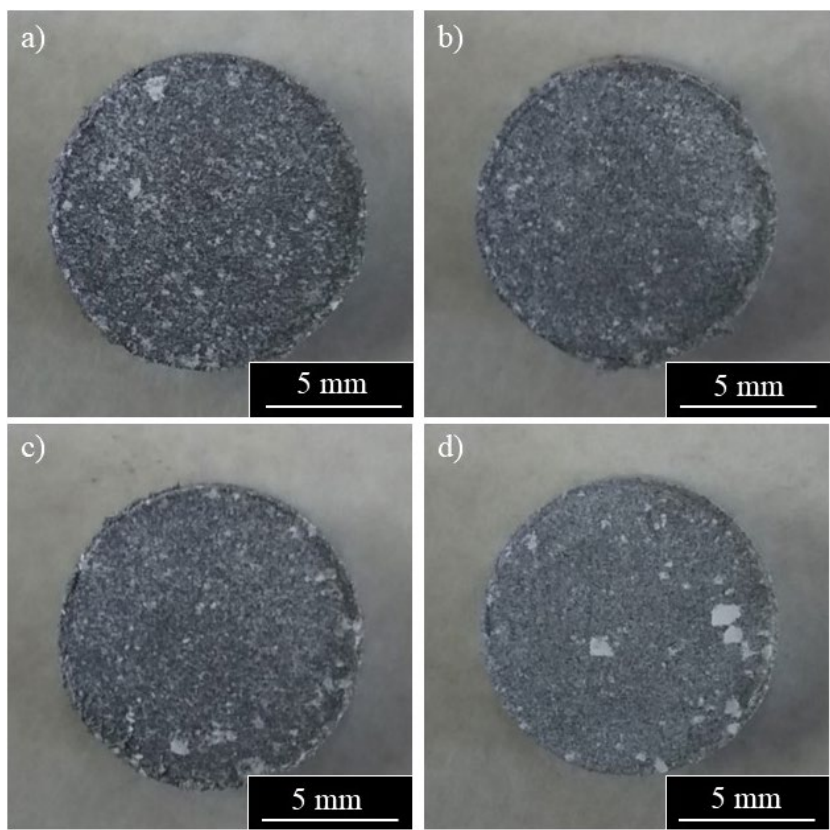

Fig. 1. Images of heat storage pellets which consisted of MEPCM and SA when pelletized and sintered under different pressure and atmosphere, respectively. a) $20 \mathrm{MPa}$-air, b) 20 $\mathrm{MPa}-\mathrm{O}_{2}$, c) $50 \mathrm{MPa}$-air and d) $50 \mathrm{MPa}-\mathrm{O}_{2}$. (Online version in color.)
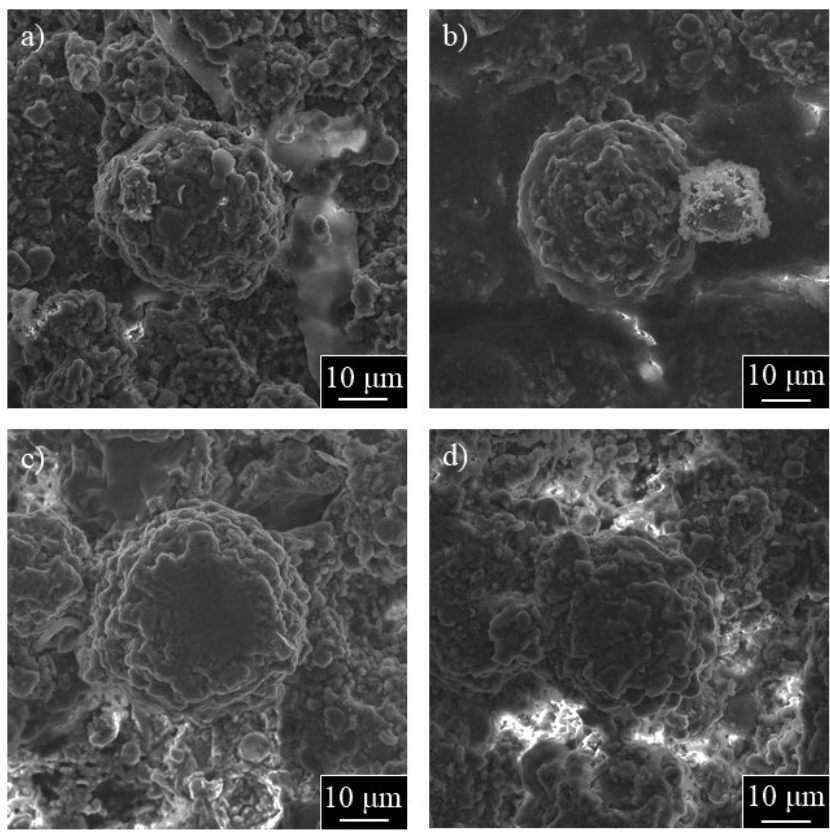

Fig. 2. SEM images of the pellets fabricated different condition. a) $20 \mathrm{MPa}-a i r$, b) $20 \mathrm{MPa}-\mathrm{O}_{2}$, c) $50 \mathrm{MPa}$-air and d) $50 \mathrm{MPa}-$ $\mathrm{O}_{2}$.

section of the pellets pelletized at $20 \mathrm{MPa}$. a-1, 2) sintered under air atmosphere and b-1, 2) $\mathrm{O}_{2}$ atmosphere. In Figs. $3-b)$ and 3-d), red areas represent Al and blue areas represent $\mathrm{O}$. Purple areas in which $\mathrm{Al}$ and $\mathrm{O}$ coexist, represent the presence of $\mathrm{Al}_{2} \mathrm{O}_{3}$. There are some regions where $\mathrm{O}$ doesn't exist in Figs. 3 a-2) and 3 b-2). In other words, some $\mathrm{Al}$ and Si doesn't coexist with $\mathrm{O}$. Therefore, elemental mapping suggests that not all the $\mathrm{Al}$ and $\mathrm{Si}$ in the pellets were oxidized. These elemental mapping results show that some PCM was not oxidized during sintering operation at fairly high temperature. Figure 4 shows schematic images inside
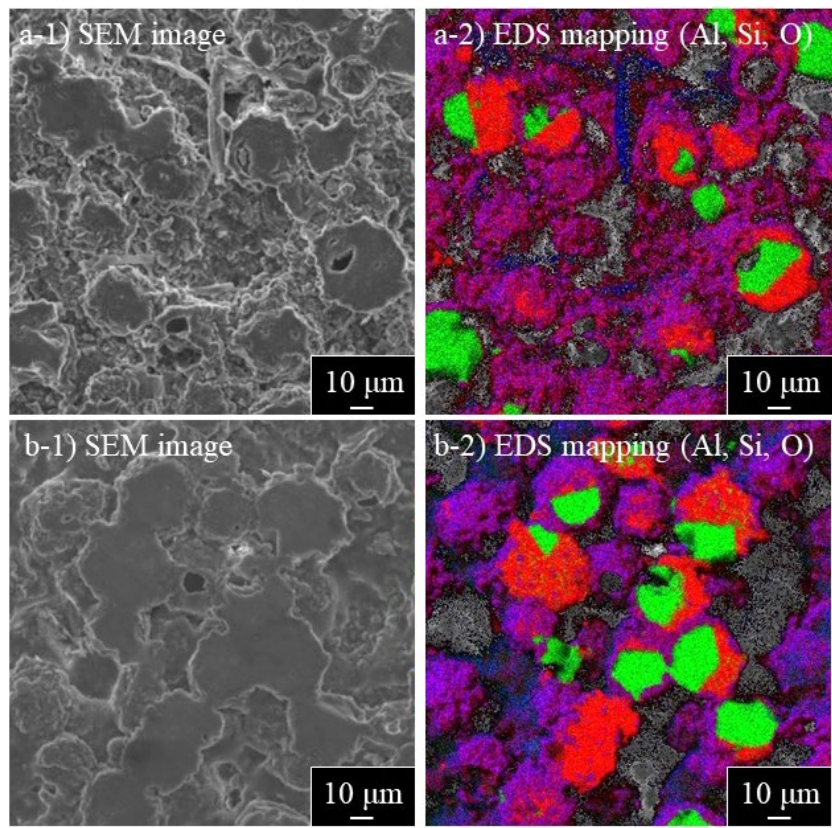

Fig. 3. SEM images and elemental mappings of the cross section of the pellets pelletized at $20 \mathrm{MPa}$. a-1,2) sintered under air atmosphere and b-1, 2) $\mathrm{O}_{2}$ atmosphere. Red area represent $\mathrm{Al}$, light green area represent $\mathrm{Si}$, and blue area represent $\mathrm{O}$. (Online version in color.)

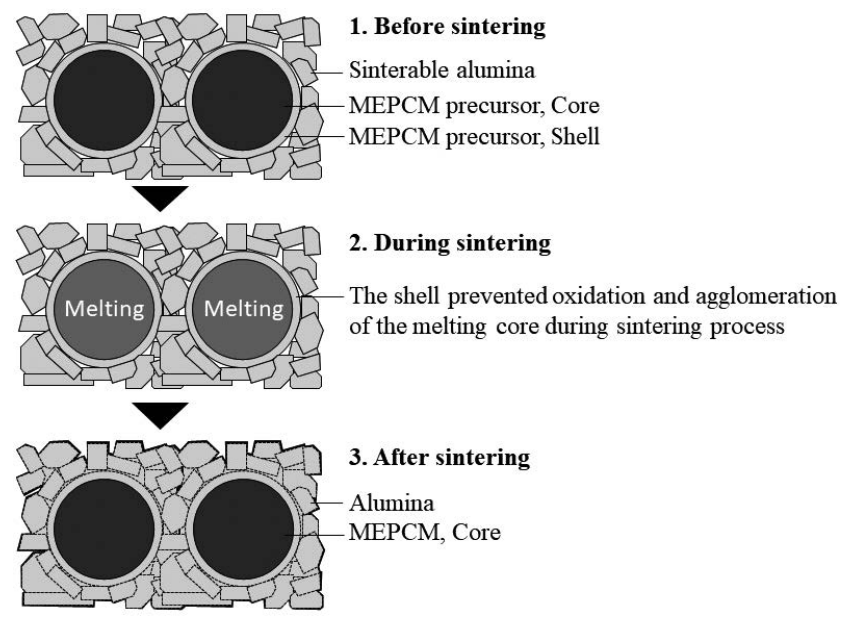

Fig. 4. Schematic images inside latent heat storage pellets before, during and after the sintering.

products before, during and after the sintering process. The shell of the MEPCM prevented the melting core from oxidation. The shell also prevented direct contact of each melting core. Thus, Al-Si alloy remains inside the products and agglomeration of metal was not observed.

Figure 5 shows XRD patterns for heat storage pellets: a-1) $20 \mathrm{MPa}$-air, b-1) $20 \mathrm{MPa}-\mathrm{O}_{2}$, c-1) $50 \mathrm{MPa}$-air and d-1) $50 \mathrm{MPa}_{2}$. Figure 5 also shows XRD patterns of sinterabe alumina. $\mathrm{Al}, \mathrm{Si}$, and $\alpha-\mathrm{Al}_{2} \mathrm{O}_{3}$ were detected in all the pellets. Figures 5 a, b, c, d, e-2) are magnified XRD patterns of the products from $20^{\circ}$ to $24^{\circ}$. The XRD spectra of each composite shows that $\mathrm{Al}_{2} \mathrm{O}_{3}$ was detected in the heat storage pellets, therefore $\mathrm{Al}$ and $\mathrm{O}$ overlapped as $\alpha-\mathrm{Al}_{2} \mathrm{O}_{3}$. The heat storage pellets, excluding the pellets pelletized at $20 \mathrm{MPa}$ and sintered under $\mathrm{O}_{2}$ atmosphere, also show the presence of $\mathrm{SiO}_{2}$. This suggests that the $\mathrm{Si}$ in the PCM was oxidized in the pellets which were sintered under air atmosphere or 

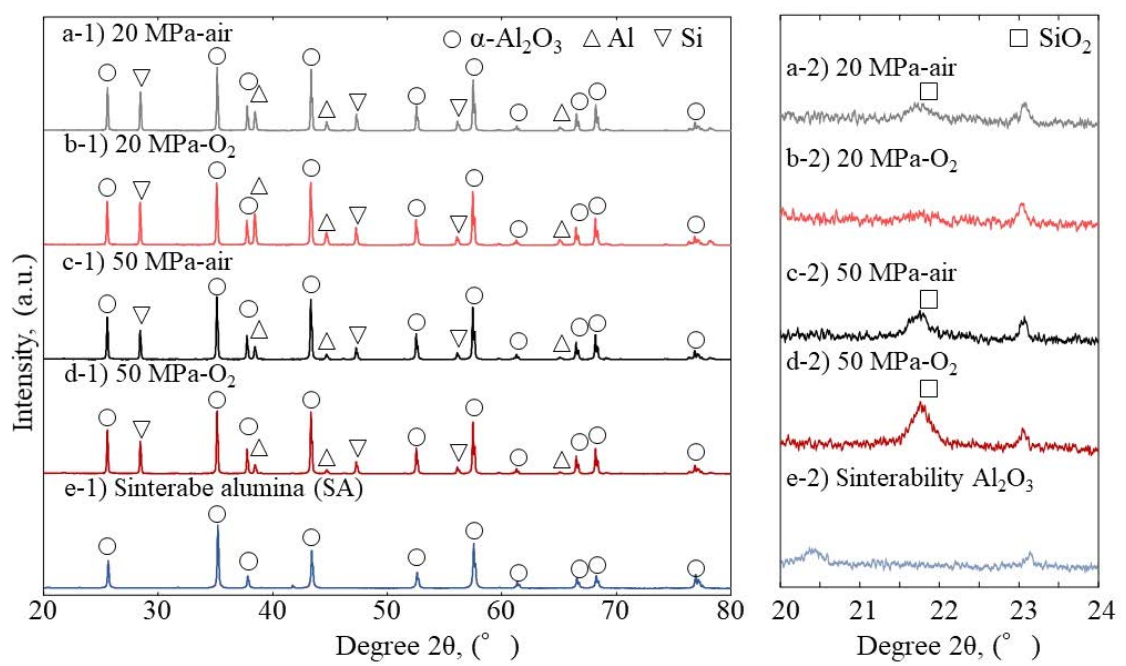

Fig. 5. XRD patterns for heat storage pellets. a-1) $20 \mathrm{MPa}$-air, b-1) $20 \mathrm{MPa}-\mathrm{O}_{2}$, c-1) $50 \mathrm{MPa}$-air and d-1) $50 \mathrm{MPa}-\mathrm{O}_{2}$ with e-1) XRD paternes of sinterable alumina. a, b, c, d, e-2) magnified XRD patterns of the products from $20^{\circ}$ to $24^{\circ}$. (Online version in color.)

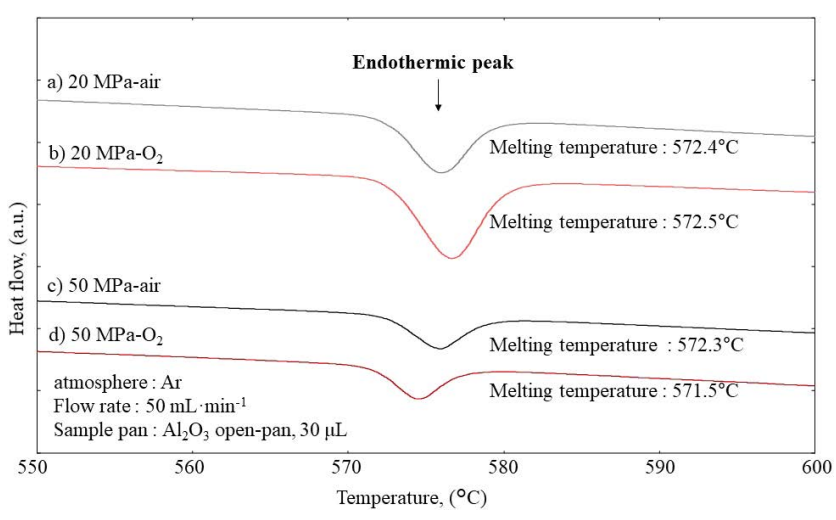

Fig. 6. DSC curves for the heat storage pellets. a) $20 \mathrm{MPa}$-air, b) $20 \mathrm{MPa}-\mathrm{O}_{2}$, c) $50 \mathrm{MPa}$-air and e) $50 \mathrm{MPa}-\mathrm{O}_{2}$. (Online version in color.)

pelletized at high pressure.

\subsection{Thermal Properties}

Figure 6 shows DSC curves for the heat storage pellets: a) $20 \mathrm{MPa}$-air, b) $20 \mathrm{MPa}-\mathrm{O}_{2}$, c) $50 \mathrm{MPa}$-air and d) 50 $\mathrm{MPa}-\mathrm{O}_{2}$. Each curve had an endothermic peak at around $577^{\circ} \mathrm{C}$, the melting temperature of $\mathrm{Al}-\mathrm{Si}$. Therefore, these peaks are solid-liquid phase transitions for Al-Si. Figure 7 shows fusion heat of the heat storage pellets shown in Fig. 6. The heat storage pellets, a) $20 \mathrm{MPa}$-air, b) $20 \mathrm{MPa}-\mathrm{O}_{2}$, c) $50 \mathrm{MPa}$-air and d) $50 \mathrm{MPa}-\mathrm{O}_{2}$, has $46.1 \mathrm{~J} \mathrm{~g}^{-1}, 73.5 \mathrm{~J} \mathrm{~g}^{-1}$, $24.4 \mathrm{~J} \mathrm{~g}^{-1}$ and $23.8 \mathrm{~J} \mathrm{~g}^{-1}$ heat storage capacity respectively.

The heat storage pellets, $20 \mathrm{MPa}-\mathrm{O}_{2}$, that were pelletized at $20 \mathrm{MPa}$ and sintered under $\mathrm{O}_{2}$ atmosphere had the highest heat storage capacities. Heat storage capacity was decreased by oxidation of PCM inside the heat storage pellets. In this study, latent heat decrease was prevented when the heat storage pellet was pelletized at $20 \mathrm{MPa}$ and sintered under $\mathrm{O}_{2}$ atmosphere. Reasons for this why this condition prevented oxidation of PCM are considered next.

To observe the mass increase, which depends on the atmosphere during sintering, TG analysis was performed of as prepared mixed powders of MEPCM precursor and SA under air or $\mathrm{O}_{2}$ flow. Figure 8 shows the result of the TG

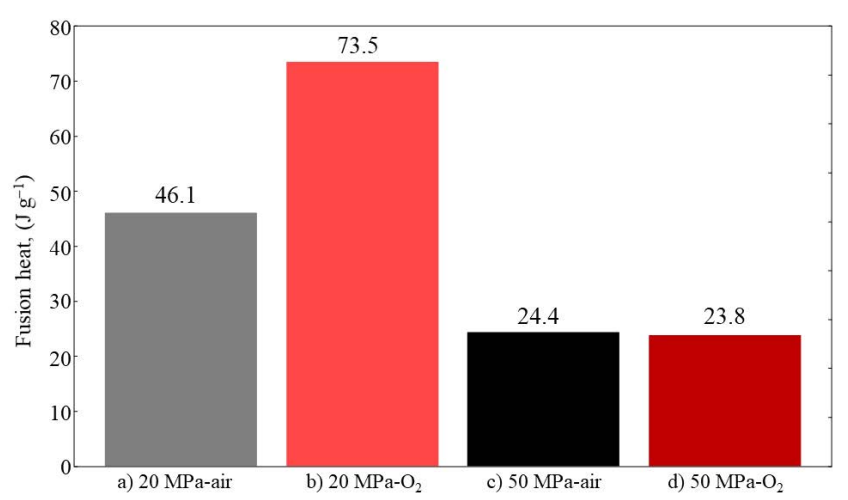

Fig. 7. Fusion heat of the heat storage pellets shown in Fig. 6. a) $20 \mathrm{MPa}-\mathrm{air}$, b) $20 \mathrm{MPa}_{2}$, c) $50 \mathrm{MPa}$-air and e) $50 \mathrm{MPa}-$ $\mathrm{O}_{2}$. (Online version in color.)

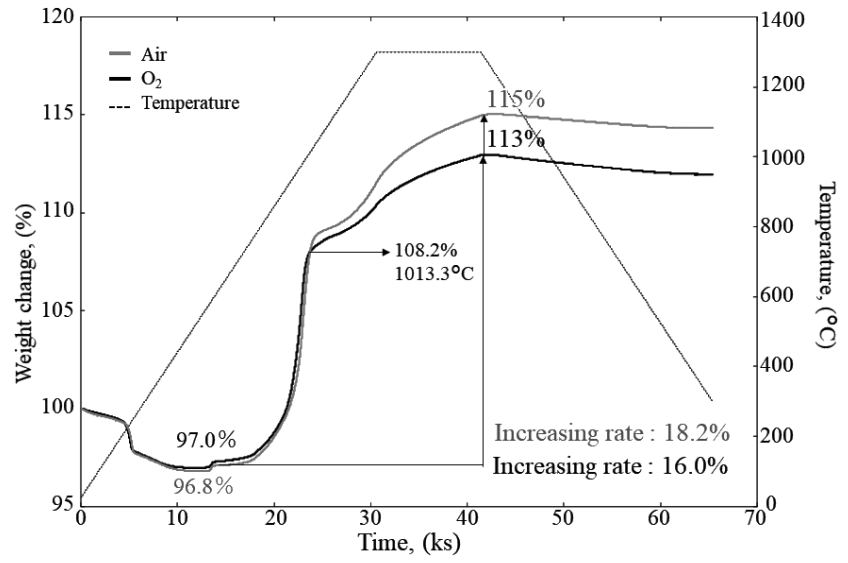

Fig. 8. TG curves of mixed powders of MEPCM precursor and $\mathrm{SA}$ under air or $\mathrm{O}_{2}$ flow.

analysis. The temperature program and atmosphere were kept same as the sintering condition. There was little difference between the two atmospheres until about $1000^{\circ} \mathrm{C}$. We observed mass decrease at around $200^{\circ} \mathrm{C}$ and mass increase started at around $590^{\circ} \mathrm{C}$. Above $1000^{\circ} \mathrm{C}$ the rate of mass increase under air flow was higher than the rate under $\mathrm{O}_{2}$ flow. Finally, there was a $2 \%$ difference in the maximum value of the weight change between air and $\mathrm{O}_{2}$. 


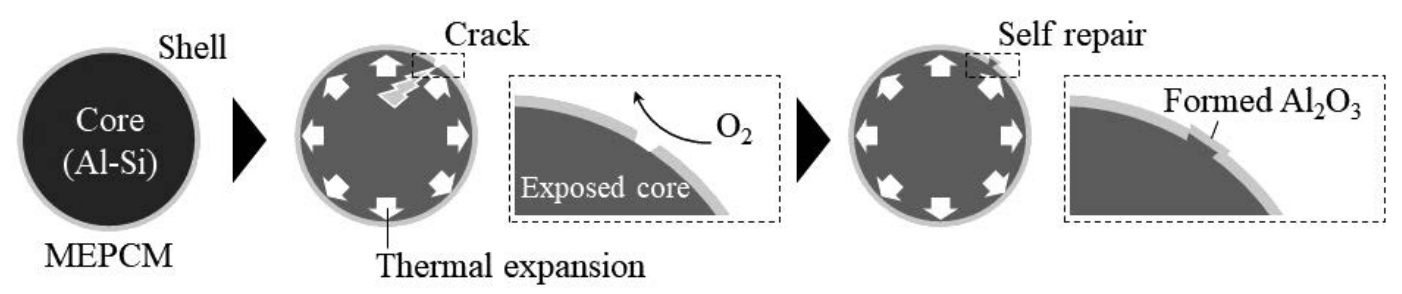

Fig. 9. A schematic image of self-repair process.

SA is stable material, thus the mass change in the TG curve is derived from MEPCM. Our previous study ${ }^{32}$ reported mass decrease due to dehydration of $\mathrm{Al}(\mathrm{OH})_{3}$ and mass increase due to oxidation of $\mathrm{Al}$ during the heat treatment of the MEPCM precursor. In the final stage of MEPCM shell formation, cracks on the MEPCM surface (caused by heat expansion of the core) are closed by $\mathrm{Al}$ oxidation. This is a self-repair process. Figure 9 shows a schematic diagram of self-repair process. This self-repair prevents further oxidation of the inner core during heat treatment and the process progresses more rapidly in atmospheres of higher partial pressure of $\mathrm{O}_{2}$. Figure 8 shows that, over $1000^{\circ} \mathrm{C}$, there is a difference in the mass increase of the samples, depending on the atmosphere. Differences in the rate of self-repair in each atmosphere are thought to cause differences in the mass increase. We can see that $\mathrm{O}_{2}$ atmosphere is advantageous for the preparation of MEPCM and heat storage pellets containing MEPCM. This is because the $\mathrm{O}_{2}$ atmosphere has a higher partial pressure of $\mathrm{O}_{2}$ than the air.

The latent heat of the heat storage pellet pelletized at $50 \mathrm{MPa}$ was lower than that of the ones pelletized at 20 $\mathrm{MPa}$. This result indicates that $50 \mathrm{MPa}$ is too high to break MEPCM during the fabrication of heat storage pellets. Cracking of the MEPCM shell caused more oxidation of the inner core. This is because the ceramic shell helps to prevent oxidation of the inner core. For this reason, high pelletizing pressure is not ideal for the fabrication of MEPCM heat storage pellets.

\section{Conclusion}

Fabrication of LHS pellets was achieved with MEPCM. The composites were fabricated in simple way by mixing MEPCM precursor and sinterable alumina, followed by compression and sintering. MEPCM precursor prevented agglomeration and combustion during the sintering step. On the other hand, oxidation of PCM was inevitable and caused loss of latent heat. When sintering temperature is higher than $1000^{\circ} \mathrm{C}, \mathrm{O}_{2}$ atmosphere allows for effective sintering. In addition, pelletizing pressure should be low enough to avoid cracking the MEPCM shell. The heat storage pellet pelletized at $20 \mathrm{MPa}$ and sintered under $\mathrm{O}_{2}$ atmosphere had highest latent heat, $73.5 \mathrm{~J} \mathrm{~g}^{-1}$. Following these findings, the next challenge is to increase the heat storage capacity.

This study demonstrates the fabrication of latent heat storage pellets with MEPCM and $\mathrm{Al}_{2} \mathrm{O}_{3}$ for high-temperature applications.

\section{REFERENCES}

1) T. Akiyama, R. Takahashi and J. Yagi: ISIJ Int., 29 (1989), 447.

2) T. Akiyama, K. Oikawa, T. Shimada, E. Kasai and J. Yagi: ISIJ Int., 40 (2000), 286.

3) T. Akiyama, H. Sato, A. Muramatsu and J. Yagi: ISIJ Int., 33 (1993), 1136.

4) A. Muramatsu, H. Sato, T. Akiyama and J. Yagi: ISIJ Int., 33 (1993), 1144.

5) E. Kasai, T. Kitajima, T. Akiyama, J. Yagi and F. Saito: ISIJ Int., 37 (1997), 1031.

6) T. Shimada, V. Kochura, T. Akiyama, E. Kasai and J. Yagi: ISIJ Int., 41 (2001), 111.

7) N. Maruoka and T. Akiyama: ISIJ Int., 42 (2002), 1189.

8) T. Mizuochi, T. Akiyama, T. Shimada, E. Kasai and J. Yagi: ISIJ Int., 41 (2001), 1423.

9) N. Shigaki, H. Tobo, S. Ozawa, Y. Ta and K. Hagiwara: ISIJ Int., 55 (2015), 2258.

10) H. Zhang, H. Wang, X. Zhu, Y.-J. Qiu, K. Li, R. Chen and Q. Liao: Appl. Energy, 112 (2013), 956.

11) T. Nomura, T. Oya, N. Okinaka and T. Akiyama: ISIJ Int., 50 (2010), 1326.

12) F. Dal Magro, A. Meneghetti, G. Nardin and S. Savino: Energy Convers. Manag., 104 (2015), 78.

13) L. Miró, J. Gasia and L. F. Cabeza: Appl. Energy, 179 (2016), 284.

14) R. Fukahori, T. Nomura, C. Zhu, N. Sheng, N. Okinaka and T. Akiyama: Appl. Energy, 170 (2016), 324.

15) B. Zalba, J. M. Marín, L. F. Cabeza and H. Mehling: Appl. Therm. Eng., 23 (2003), 251.

16) M. M. Farid, A. M. Khudhair, S. A. K. Razack and S. Al-Hallaj: Energy Convers. Manag., 45 (2004), 1597.

17) A. Sharma, V. V. Tyagi, C. R. Chen and D. Buddhi: Renew. Sustain. Energy Rev., 13 (2009), 318.

18) A. Kaizawa, H. Kamano, A. Kawai, T. Jozuka, T. Senda, N. Maruoka, N. Okinaka and T. Akiyama: ISIJ Int., 48 (2008), 540.

19) P. Blanco-Rodríguez, J. Rodríguez-Aseguinolaza, E. Risueño, A. Faik, M. Tello and S. Doppiu: Energy, 75 (2014), 630.

20) E. Risueño, A. Gil, J. Rodríguez-Aseguinolaza, M. Tello, A. Faik and B. D’Aguanno: J. Therm. Anal. Calorim., 129 (2017), 885.

21) N. Gokon, S. Nakamura, T. Yamaguchi and T. Kodama: Energy Procedia, 69 (2015), 1759.

22) J. E. Rea, C. J. Oshman, A. Singh, J. Alleman, P. A. Parilla, C. L. Hardin, M. L. Olsen, N. P. Siegel, D. S. Ginley and E. S. Toberer: Appl. Energy, 230 (2018), 1218.

23) C. E. Andraka, A. M. Kruizenga, B. A. Hernandez-Sanchez and E. N. Coker: Energy Procedia, 69 (2015), 726.

24) G. Nardin, A. Meneghetti, F. Dal Magro and N. Benedetti: Appl. Energy, 136 (2014), 947.

25) F. Dal Magro, M. Jimenez-Arreola and A. Romagnoli: Appl. Energy, 208 (2017), 972.

26) N. Maruoka, K. Sato, J. Yagi and T. Akiyama: ISIJ Int., 42 (2002), 215.

27) N. Maruoka, T. Mizuochi, H. Purwanto and T. Akiyama: ISIJ Int., 44 (2004), 257.

28) N. Maruoka and T. Akiyama: ISIJ Int., 50 (2010), 1305.

29) T. Nomura, J. Yoolerd, N. Sheng, H. Sakai, Y. Hasegawa, M. Haga and T. Akiyama: Sol. Energy Mater. Sol. Cells, 193 (2019), 281.

30) T. Nomura, N. Sheng, C. Zhu, G. Saito, D. Hanzaki, T. Hiraki and T. Akiyama: Appl. Energy, 188 (2017), 9.

31) T. Nomura, J. Yoolerd, N. Sheng, H. Sakai, Y. Hasegawa, M. Haga, G. Saito and T. Akiyama: Sol. Energy Mater. Sol. Cells, 187 (2018), 255.

32) N. Sheng, C. Zhu, G. Saito, T. Hiraki, M. Haka, Y. Hasegawa, H. Sakai, T. Akiyama and T. Nomura: J. Mater. Chem. A, 6 (2018), 18143.

33) N. Sheng, C. Zhu, H. Sakai, T. Akiyama and T. Nomura: Sol. Energy Mater. Sol. Cells, 191 (2019), 141. 